\title{
Identification of Groundwater Recharge Zones of Bhavani Watershed using Geo Spatial Techniques
}

\author{
A. Valliammai ${ }^{1}$, G. Thiyagarajan ${ }^{2 *}$ and Balaji Kannan $^{3}$ \\ ${ }^{1}$ Agricultural Research Station, Tamil Nadu Agricultural University, \\ Bhavanisagar - 638 451, India \\ ${ }^{2}$ Water Technology Centre, Tamil Nadu Agricultural University, Coimbatore-641 003, India \\ ${ }^{3}$ Department of Soil and Water Conservation Engineering, Agricultural Engineering College \\ and Research Institute, Tamil Nadu Agricultural University, Coimbatore - 641 003, India \\ *Corresponding author
}

\section{A B S T R A C T}

\begin{tabular}{|l|}
\hline K e y w o r d s \\
Geo-Informatics, \\
Groundwater \\
recharge zones, \\
Remote sensing, \\
Thematic layers
\end{tabular}

\section{Introduction}

Water is an indispensable constituent of everyday life and it is widely distributed in nature so that it may be available quickly and easily. However, with increasing population
Groundwater is a dynamic and replenishable natural resource, but in hard rock terrains, availability of groundwater is of limited extent and is depleting in many areas due to its large scale withdrawal for various sectors. Groundwater recharge such as rainwater harvesting is essential in order to improve ground water level and quality. The main objective of the study is to identify suitable sites for groundwater recharge in the study area through Geospatial technology. To attain this Remote Sensing Technology is the good tool in mapping such geological features related to groundwater recharge. The study area of Bhavnai watershed (4B2D1) of LBP basin has the area of around $712 \mathrm{~km}^{2}$. Groundwater recharge zones were identified via seven parameters adjoining with the emerging technology of Remote Sensing and GIS. The thematic layers were considered in this study are Geology, Geomorphology, rainfall, slope, lineament, soil and drainage which were prepared using the conventional data. All these themes and their individual features were then assigned weights according to their importance in groundwater recharge. The thematic layers were finally integrated to yield a groundwater potential zone map, As far as the groundwater potential zones are concerned $75 \%$ of the study area falls in zones of moderate category, $18 \%$ falls in good zone and $7 \%$ under very good zone category. 
water resources is essential for development of the country Besides targeting of groundwater, to delineate the groundwater recharge zones is also an important factor for identifying artificial recharge structures (Saraf and Choudhury, 1997).

Remote sensing and GIS are playing a rapidly increasing role in the field of hydrology and water resources development. One of the greatest advantages of using remote sensing data for groundwater investigations and monitoring is its ability to generate information in spatial and temporal domain, which is very crucial for successful analysis, prediction and validation (Saraf, 1999).

An integrated study covering the aspect of groundwater recharge is a crucial requirement of the present day (Choudhury, 1999). The present work is an attempt towards this direction.

The study focuses on development of remote sensing and GIS based analysis and methodology in identifying the groundwater recharge zones.

\section{Materials and Methods}

The present study was taken up in the Bhavani watershed of LBP basin of the Tamil Nadu. A study was conducted for identification of potential groundwater rechargeable zone in Bhavnai watershed.

\section{Location}

The study area of Bhavani watershed (4B2D1) falls under the catchment area of the LBP basin. The watershed area of about $712 \mathrm{~km}^{2}$. The river Bhavani flows into the study area and the location map of the area is given in Figure 1. The watershed map was obtained from AED, Erode and was used for base map preparation. The study area boundary was digitized.

Fig.1 Location of Bhavani watershed

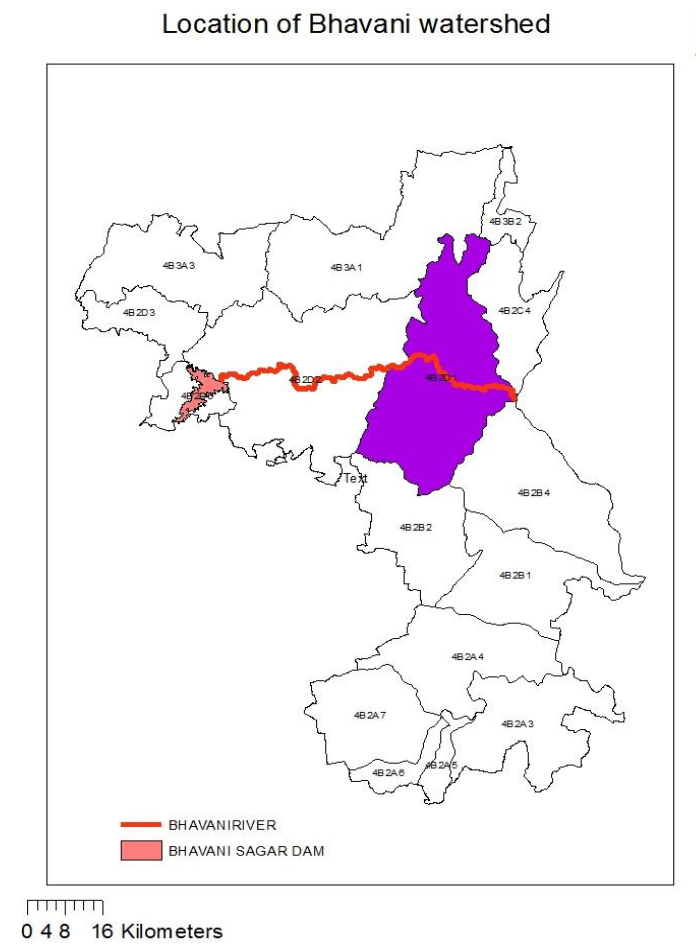




\section{Thematic maps}

Groundwater recharge zones were identified via seven parameters adjoining with the emerging technology of Remote Sensing and GIS. The thematic layers were considered in this study are Soil, Land use, Geology, Geomorphology, slope, lineament and drainage which were prepared using the conventional data

The digitized soil map was obtained from Remote Sensing and GIS Department, TNAU, Coimbatore, and used for the study. The study area consists of agricultural land, waste land, wasteland, water bodies and built-up lands (Fig. 2). The geology of the study area is grouped into two category as 'moderate' (Garnet gneiss), 'poor' (Charnockites) (Fig. $3)$. The slope map of the study area was prepared from ASTER digital elevation data.

Drainage map was extracted using the ASTER DEM (Fig. 4). The slope value ranges between 0 and $35 \%$ (Fig. 5) (Saraf and Jain, 1996).

\section{Weighted overlay analysis}

In order to find out the effective recharge zones, the weighted overlay was applied according to the priority of thematic layers in the study area. Hence, the following weightage were assigned according to their influencing characters viz., soil $=15$, Land use $=10, \quad$ Drainage $=15, \quad$ Geology $=5$, Gepmorphology-25. Slope $=15$, Lineament $=$ 15 . During the weighted overlay analysis, the rank was assigned in terms of 1,2, 3 and 4 for each individual parameter of thematic layers to obtain the recharge zones in terms of good, moderate, poor and very poor zones (Subba Rao et al., 2001).

\section{Results and Discussion}

The study of identifying the rechargeable area was carried out in the Bhavani watershed of
LBP basin Agriculture crop is the dominant land use type and occupies about $60 \%$ of the area followed by Forest land (26\%) and the remaining area was occupied by other classes. The majority of the study area is occupied with Clay loam (41\%).

The crop lands as well as plantations are an excellent site for groundwater exploration is provided with the highest rank of due to adversely affected recharge of the groundwater regime by reduced infiltration. The elevation ranges from 156 to $1549 \mathrm{~m}$ and it shows the sloping terrain of the study area. From the DEM, the slope (\%) was derived with the range of $0-38 \%$. The drainage distribution pattern was identified as 1st, 2nd, 3 rd \& 4th order streams.

Weighted Overlaying Analysis is done by combining the data from the multiple data categories. During the process of overlay, the thematic maps and their attributes were intercepted and a new thematic map with attributes was obtained.

This method is a simple and straightforward method for combined analysis of multi class map. In Weighted Overlay Method, the ranks and weights have been assigned to various classes of different themes like geology, land use pattern, soil type, slope and drainage according to its priority and importance to support the groundwater recharge.

The weightages of each criterion was finalized on the basis of the ranges of the maximum and minimum values within each theme. After these weighted overlay analysis the groundwater recharge zones were obtained (Fig. 6). From the recharge zone map it was found that $75 \%$ of the study area falls in zones of moderate category, $18 \%$ falls in good zone and $7 \%$ under very good zone category.. The detailed composite map has been shown to very useful for selecting the sites of groundwater rechargeable zone. 
Fig.2 Landuse map

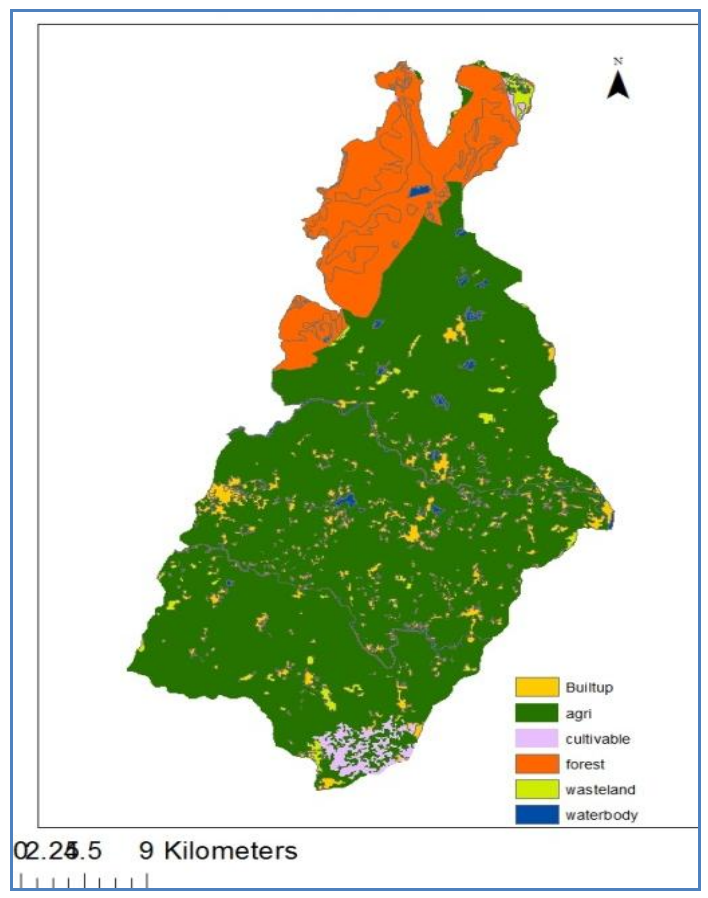

Fig.4 DEM map

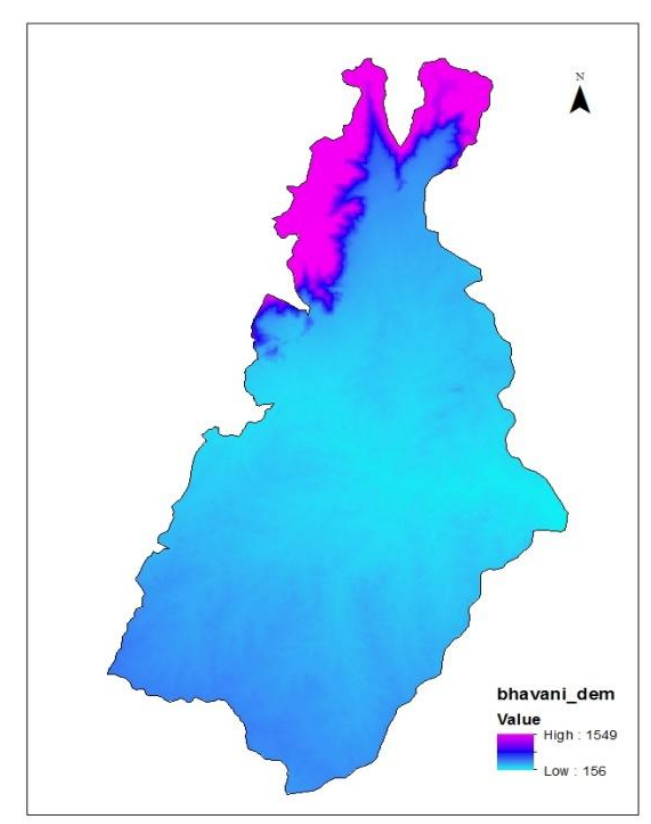

$\underset{01.53}{7} \coprod_{9}$ Kilometers
Fig.3 Geology map

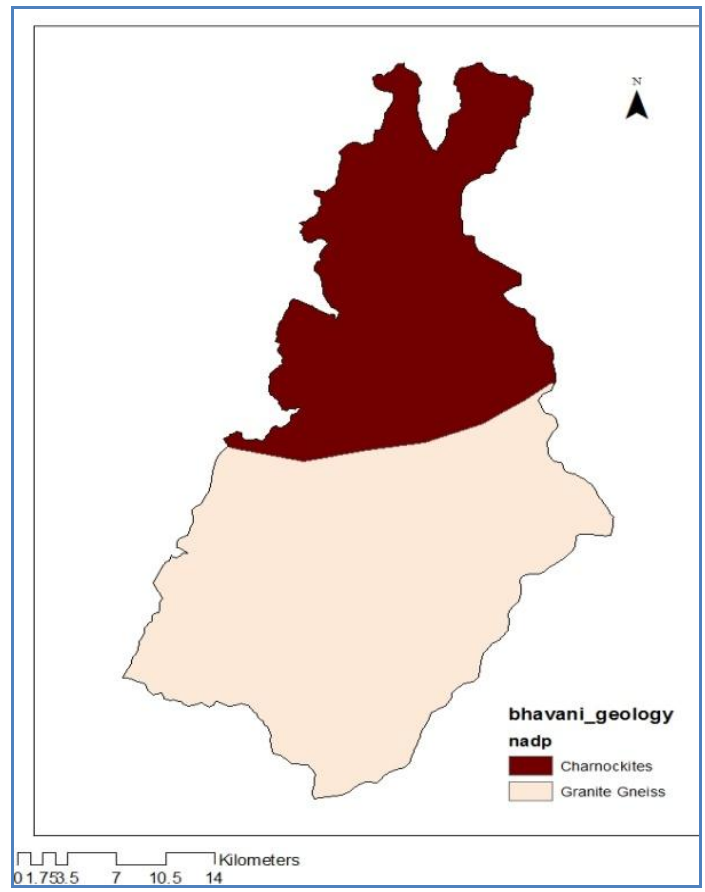

Fig.5 Slope map

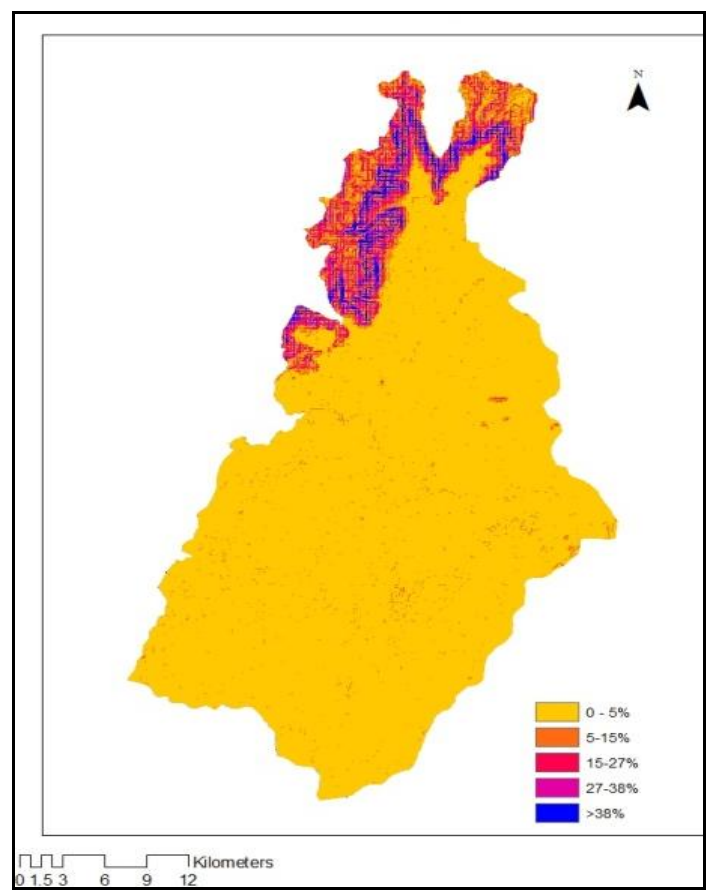


Fig.6 Suitable sites for rainwater harvesting map

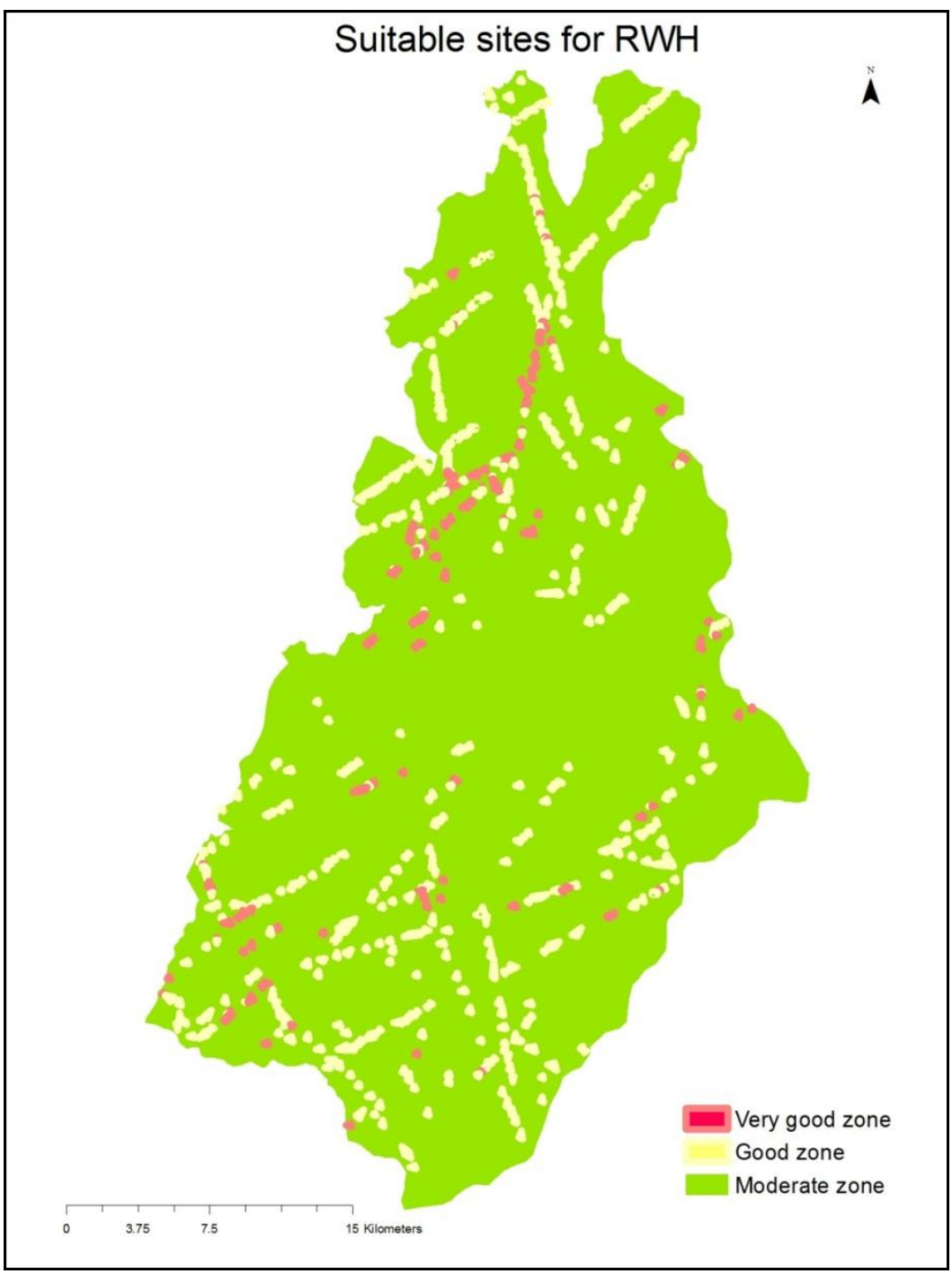

Water harvesting structures are extremely important to conserve precious natural resources like, soil and water, which is depleting day by day at alarming rate.

The study area of Bhavani watershed which comes under the water deficit zone. Keeping this in view this study area was selected for identifying suitable ground water recharge zone using Remote Sensing and GIS techniques.

In this study, different thematic layers were prepared from the different data sources and weightages were assigned based on the priority categories of groundwater recharge. The suitable rechargeable areas were identified and the respected zones are classified by three categories as moderate, good, and very good.

\section{References}

Choudhury, P. R. 1999. Integrated remote sensing and GIS techniques for groundwater studies in part of Betwa basin, Ph.D. Thesis, Department of Earth Sciences, University of Roorkee, 
India.

Saraf, A.K. and Jain, S.K., 1996. Integrated use of remote sensing and GIS methods for groundwater exploration in parts of Lalitpur District, U.P., International conference on Hydrology and Water Resources, New Delhi, Dec 20-22, 1993, 251-259.

Saraf, A. K. and Choudhury, P. R., 1997. Integrated Application of Remote Sensing and GIS Groundwater exploration in hard rock terrain, Proceedings. Int. Symp. on Emerging trends in Hydrology, Department of
Hydrology, Roorkee, September 2527, 1997, Vol. I, 435-442.

Saraf, A. K. 1999. A report on Landuse Modeling in GIS for Bankura District, Projet sponsored by DST, NRDMS division, Govt. of India.

Subba Rao, N., G. K. J. Chakradhar and V. Srinivas. 2001. Identification of groundwater potential zones using remote sensing techniques in and around Guntur town, Andhra Pradesh, India. J. Indian Soc. Remote Sensing. 29 (1\&2): 69-78.

\section{How to cite this article:}

Valliammai, A., G. Thiygarajan and Balaji Kannan. 2019. Identification of Groundwater Recharge Zones of Bhavani Watershed using Geo Spatial Techniques. Int.J.Curr.Microbiol.App.Sci. 8(10): 1574-1579. doi: https://doi.org/10.20546/ijcmas.2019.810.183 